\title{
Practice-oriented Learning as a Way to Meet Employers' Requirements to Graduates
}

\author{
http://dx.doi.org/10.3991/ijep.v4i2.3440 \\ Chuchalin, M. Minin and N. Vyuzhanina \\ National Research Tomsk Polytechnic University. Tomsk. Russia
}

\begin{abstract}
The article considers the current state of engineering education in Europe in general and in Russia in particular in the light of the need to meet employers' requirement to graduates, and the role of practice-oriented learning technologies in this process. The demand for graduates on the labour market and their competitiveness is seen as the main indicator of the education system ability to react and adapt to the market demands. Thus the employers' requirements should be one of the most important drivers for the learning process. And the practice-oriented learning technologies are given as the most effective answer to these needs as they imply involvement of the employer and solution of real-world tasks and problems.
\end{abstract}

Index Terms-employers' requirements, practice-oriented learning technologies

\section{INTRODUCTION}

As it is stated in the London Communique : “... As we look ahead we recognise that, in a changing world, there will be a continuing need to adapt our higher education systems to ensure that EHEA remains competitive and can respond effectively to the challenges of globalisation..." [1]. So the need for the education system being able to provide appropriate and timely responses to emerging challenges of the society is evident. The demand for graduates on the labour market, their competitiveness is one of the indicators of such ability.

Accordingly, the academic community is widely discussing how yet to prepare specialists who are modern, competitive, demanded by the market, and if there are special methods to train them.

\section{CurRent State of ENGINEERING EduCATION}

The Bologna Declaration, which clearly defined goal is to create a European Area for Higher Education, which will enhance the employability of citizens and increase the international competitiveness of European higher education, states that academic standards must be set and maintained at a level appropriate to the requirements of industry and universities [2].

In accordance with the Concept of Russian Education Modernization, sustainable functioning and development of the domestic education system is as well associated with its emergence as the most open and flexible system that quickly reacts to the state and trends of the labour market.

But today there is a contradiction between the engineers training quality and the employers' requirements to them.
It generates a problem that affects the state of engineering in the country.

According to the academic and professional communities that gathered for the All-Russian Scientific and Practical Conference "Approaches to Development of the National Doctrine of Engineering Education of Russia in the New Industrialization" organised in December 2012 by the Association for Engineering Education of Russia (AEER), explanation for this contradiction lies in nonalignment of principles, content and forms of training of modern specialists in engineering and technology (bachelors, masters, engineers) with the requirements of modern production that develops by the laws of the market economy [3]. Competitiveness of industry, its ability to exploit technological advances and provide quality products and services depends heavily on adaptable and competence specialists.

What are the differences between requirements of employers and university professors for future engineers?

According to AEER President Professor Yury Pokholkov, "industry representatives want a graduate, who will come to them after a university with a diploma testifying his qualifications in engineering and technology, able to think independently and systematically, effectively solve production problems using the skills that he received in the university, that he is able to work in teams, knows business processes and business environment in general, is able to perceive and generate innovative ideas, to introduce with arguments himself, his idea, to persuade the audience, to win the interest, that he was able to use foreign languages in his work. And how much attention in universities is paid to development of such competences? Mainly universities organise their work so that graduates have the knowledge. Have you obtained a diploma? So you are a specialist of high quality" [4].

Indeed, the content of engineering educational programmes and teaching and learning technologies used today, as a rule, do not allow forming future specialists qualities required by employers. Universities organise their work commonly in such a way that graduates, first of all, have knowledge of the subjects studied in the university. Accordingly, criteria for assessing future engineers training quality are shifted to assessment of their knowledge.

The quality of future graduates is determined by the quality of all elements of their training process. It is worth noting that despite the importance of proper planning of learning outcomes and educational programmes content, the choice of appropriate technologies to implement them is not less responsible. In other words, it is necessary to use such forms of organization and methods of activating 
PAPER

PRACTICE-ORIENTED LEARNING AS A WAY to MEET EMPLOYERS’ REQUIREMENTS TO GRADUATES

educational activities of teachers and students which in the optimal combination will be most effective for achieving planned learning outcomes - competencies of graduates. The use of proper teaching and learning technologies is strongly connected with the need to improve pedagogical competences of teachers, to train teachers to use appropriate teaching and learning technologies. And most commonly required orientation on research in the qualification profile of teachers should be balanced with teaching abilities.

Moreover, in order that the university could actually develop required student competencies it is necessary to change the current higher education practice of artificial separation of fundamental and applied sciences, which leads to a natural decrease in students' interest because students do not understand why they need the knowledge they receive, and what is their role in the chosen subject area and professional field. Shortly, possibility of acquired knowledge practical application is underrepresented in the learning process.

The need for orientation on practice is also stated in the Learning and Employability series of the Higher Education Academy. Interviews with 97 newly recruited graduates and 117 of their more experienced workplace colleagues indicated that practical problem-working and contributory skilled practices were often components of success in employment. So the curriculum should be designed to help learners to understand the subject content and to be interested in developing skills as well, that is both academic intelligence and "practical intelligence" should be taking into account. The focus on students' employability are to be also maintained in the learning, teaching and assessment methods as well, and they need to make the world of work "become "real", and therefore to be personally engaging and include active involvement of employers. Traditional methods are not denied but the concern is expressed that such methods are unlikely to be sufficient. $[5,6]$

The Recommendations of the above-mentioned conference also state that more active participation of business and industry in university activities to train today's professionals in engineering and technology will be useful, including the provision of opportunities for universities to conduct practical training for teachers and for students, to obtain working profession categories by them, to use facilities, to create educational laboratories in universities and conditions for work of base chairs within enterprises. And promising direction of this interaction is the development of practice-oriented learning technologies [3].

Practice-Oriented The Bologna Declaration, which clearly defined goal is to create a European Area for Higher Education, which will enhance the employability of citizens and increase the international competitiveness of European higher education, states that academic standards must be set and maintained at a level appropriate to the requirements of industry and universities [2].

In accordance with the Concept of Russian Education Modernization, sustainable functioning and development of the domestic education system is as well associated with its emergence as the most open and flexible system that quickly reacts to the state and trends of the labour market.

But today there is a contradiction between the engineers training quality and the employers' requirements to them.
It generates a problem that affects the state of engineering in the country.

According to the academic and professional communities that gathered for the All-Russian Scientific and Practical Conference "Approaches to Development of the National Doctrine of Engineering Education of Russia in the New Industrialization" organised in December 2012 by the Association for Engineering Education of Russia (AEER), explanation for this contradiction lies in nonalignment of principles, content and forms of training of modern specialists in engineering and technology (bachelors, masters, engineers) with the requirements of modern production that develops by the laws of the market economy [3]. Competitiveness of industry, its ability to exploit technological advances and provide quality products and services depends heavily on adaptable and competence specialists.

What are the differences between requirements of employers and university professors for future engineers?

According to AEER President Professor Yury Pokholkov, "industry representatives want a graduate, who will come to them after a university with a diploma testifying his qualifications in engineering and technology, able to think independently and systematically, effectively solve production problems using the skills that he received in the university, that he is able to work in teams, knows business processes and business environment in general, is able to perceive and generate innovative ideas, to introduce with arguments himself, his idea, to persuade the audience, to win the interest, that he was able to use foreign languages in his work. And how much attention in universities is paid to development of such competences? Mainly universities organise their work so that graduates have the knowledge. Have you obtained a diploma? So you are a specialist of high quality" [4].

Indeed, the content of engineering educational programmes and teaching and learning technologies used today, as a rule, do not allow forming future specialists qualities required by employers. Universities organise their work commonly in such a way that graduates, first of all, have knowledge of the subjects studied in the university. Accordingly, criteria for assessing future engineers training quality are shifted to assessment of their knowledge.

The quality of future graduates is determined by the quality of all elements of their training process. It is worth noting that despite the importance of proper planning of learning outcomes and educational programmes content, the choice of appropriate technologies to implement them is not less responsible. In other words, it is necessary to use such forms of organization and methods of activating educational activities of teachers and students which in the optimal combination will be most effective for achieving planned learning outcomes - competencies of graduates. The use of proper teaching and learning technologies is strongly connected with the need to improve pedagogical competences of teachers, to train teachers to use appropriate teaching and learning technologies. And most commonly required orientation on research in the qualification profile of teachers should be balanced with teaching abilities.

Moreover, in order that the university could actually develop required student competencies it is necessary to change the current higher education practice of artificial 
PAPER

Practice-ORIENTEd LEARNING AS A WAy to MEET EMPLOYERS’ REQUIREMENTS to GRAdUATES

separation of fundamental and applied sciences, which leads to a natural decrease in students' interest because students do not understand why they need the knowledge they receive, and what is their role in the chosen subject area and professional field. Shortly, possibility of acquired knowledge practical application is underrepresented in the learning process.

The need for orientation on practice is also stated in the Learning and Employability series of the Higher Education Academy. Interviews with 97 newly recruited graduates and 117 of their more experienced workplace colleagues indicated that practical problem-working and contributory skilled practices were often components of success in employment. So the curriculum should be designed to help learners to understand the subject content and to be interested in developing skills as well, that is both academic intelligence and "practical intelligence" should be taking into account. The focus on students' employability are to be also maintained in the learning, teaching and assessment methods as well, and they need to make the world of work "become "real", and therefore to be personally engaging and include active involvement of employers. Traditional methods are not denied but the concern is expressed that such methods are unlikely to be sufficient. [5, 6]

The Recommendations of the above-mentioned conference also state that more active participation of business and industry in university activities to train today's professionals in engineering and technology will be useful, including the provision of opportunities for universities to conduct practical training for teachers and for students, to obtain working profession categories by them, to use facilities, to create educational laboratories in universities and conditions for work of base chairs within enterprises. And promising direction of this interaction is the development of practice-oriented learning technologies [3].

\section{TECHNOLOGIES FOR ADAPTABILITY AND QUALITY OF ENGINEERING EDUCATION}

Tomsk Polytechnic University studied and uses in the educational process extensive experience of Aalborg University (Denmark), Griffith University and Victoria University (Australia), University of Leuven (Belgium), University of Southampton (UK), Delft University of Technology (Netherlands), Vienna University of Applied Sciences (Austria) and many others.

If to consider international experience, it is necessary to note the wide use of practice-oriented learning technologies with active involvement of the employer and solution of actual production problems already during the learning.

One of the most widespread methods that have proven its effectiveness in respect of compliance with the above mentioned needs is the problem-based learning.

Problem-based learning (PBL) is an instructional method where students "learn to learn", working cooperatively in groups to seek solutions to real world problems. PBL prepares students to think critically and analytically, and to find and use appropriate learning resources.

PBL aims to enhance students' competence in such areas as adaptation and participation in change; application of problem solving in new and future situations; creative and critical thought; adoption of holistic approach to problems and situations; appreciation of diverse viewpoints; successful team collaboration; identification of learning weaknesses and strengths; promotion of self-directed learning; effective communication skills; augmentation of knowledge base; leadership skills; utilization of relevant and varied resources [7].

A striking example of its implementation is Aalborg University (AAU).

Since Aalborg University was established in 1974, all the University programmes have been based on a unique learning model which is also called "The Aalborg model". This model is recognized nationally and internationally as advanced and effective learning model and the brand of Aalborg University. In support of this fact it is also worth noting that UNESCO established the Chair in Problem Based Learning at Aalborg University. Study of the Organization for Economic Cooperation and Development showed that this model is close to optimal for learning process [8].

Aalborg University uses the unique approach that include both problem-base and project-organised learning. The Aalborg model essence is that teaching methods and student work are connected with the solution of practiceoriented problems that are being solved by students almost independently working in groups through project work.

In our opinion, one of the main advantages of the Aalborg model is high motivations of students to gain new knowledge in such organization of the educational process. Of course, not all students are capable to learn in such an environment, when at the beginning of training, with complete uncertainty and lack of knowledge necessary to solve problems, they have to work on their own (!) on the project topic. Thereby the first year student dropout level is more than 20\% [8]. But later on (according to AAU teachers) students change, they become more selfreliant, self-organized, self-confident in their strengths, knowledge and skills. Senior students easily take for complex industrial problems and solve them. The motto of the university is the well-known Chinese proverb: "Talk to me and I will forget, show me and I will remember, involve me and I will understand, step back and I will act".

As for any proofs for this model being superior to traditional teaching, it is difficult to directly compare these two different teaching methods but it is possible to look at the learning results and students' perception of their learning, the students of Aalborg University and Technical University of Denmark, which has the traditional system of teaching and learning, conducted a survey that showed that these two universities are similar in respect of professional competences but the PBL students are better in personal competences compared with "traditional" students [9].

The Worldwide CDIO Initiative could be also provided as a strong example. It is the international project aimed at elimination of discrepancies between theory and practice in engineering education. The new approach assumes strengthening practical orientation of engineering education and introduction of the system of problem-oriented and project-oriented training.

The CDIO project was initiated by researchers, industry representatives, engineers and students of Massachusetts Institute of Technology in the late 1990-s. According to the CDIO concept, modernization of basic engineering education is to train graduates for complex engineering activities. It includes the study of market needs for engi- 
PAPER

PRACTICE-ORIENTED LEARNING AS A WAY to MEET EMPLOYERS’ REQUIREMENTS TO GRADUATES

neering products and search of possibilities to meet them, production planning, project management, etc.

TPU is the first Russian university that became the member of the leading world universities initiative of leading on modernization of engineering education. With 97 collaborating educational institutions worldwide, the CDIO Initiative is expanding constantly [10].

The CDIO Initiative is actively supported by professional engineering community and accreditation agencies. For example, Boeing Company, the largest global manufacturer of aviation, space and military equipment, and the ABET actively participated in working out the list of competences for graduates of engineering programmes.

In general, on basis of the world practice study it can be said that the practice-oriented learning technologies allow:

- to reduce significantly the adaption period for the graduate to production conditions;

- graduates to acquire experience of team and/or independent work on solving real-world tasks and projects that shape their ability to see problems and find ways to solve them, including non-standard ways, as well as to acquire experience of public presentation of their work results;

- graduates to develop not only standard competences but also exclusive competences making them highlydemanded in a professional environment and ensuring a successful business career;

- to ensure participation of employers in the training process, that, in turn, allows learners not only to get "first-hand" practical knowledge and skills, but to quickly learn changing needs of employers;

- to enrich educational programmes with the latest developments in the corresponding field of engineering and technology;

- and much more

\section{EXPERIENCE OF PRACTICE-ORIENTED TECHNOLOGIES USE IN TPU}

As it was already mentioned above, Tomsk Polytechnic University actively studies, introduces and practices modern practice-oriented learning technologies. One of the first experiences of practice-oriented technologies use was within the Elite Technical Education Programme, the purpose of which is to prepare professionals who are capable for comprehensive research, design and entrepreneurial activities aimed at development and production of competitive scientific and technical products and rapid positive changes in the country economy.

Selection for study on the Elite Education Programme is made by a special commission on the basis of test results. Specifically developed by TPU staff, the test consists of 50 tasks based on school mathematics and physics courses and is divided into tasks that test ability to learn in this department (ability to compare, to think logically, etc.).

The Elite Education Programme comprises: individual study plan; advanced fundamental training; study of courses designed to develop skills in project work, teamwork, ability to formulate and solve problems of innovative development; training and research work of students on the basis of problem-based and project-organized learning.
The use of micro-projects in physics labs at the Elite Technical Education programme can be presented as one of the example of problem-based and project-organised learning technologies implementation in the educational process. The goal is to make changes to the traditional process and development of the learners' abilities to apply scientific, mathematical and engineering knowledge, to plan and conduct an experiment, analyze and interpret data, design systems, their components or processes in accordance with the given tasks, work in teams on interdisciplinary topics.

A teacher selects a physical phenomenon or law for research. A team of students is to develop approaches to the study of proposed research subject, to search for possible research variants, to choose the one that is affordable and feasible by a team with minimal involvement of technical staff of a supporting chair.

In the course of the study a team needs to thoroughly examine the theoretical part, create a model - a research stand, develop measurement guidelines, measure, process data and prepare a research report with a presentation. The final stage of a micro-project is its defence.

The experience of use of computer tools for the study of theoretical models of phenomena and processes in the laboratory practical course is also very interesting. Experience of development and use in the learning process of computer labs for the study of physical models allows offering their detailed research methodology on the basis of accuracy and clarity of computer models. This makes students more fully understand the physical sense laid down in the model. Labs are carried out at one's own pace and are offered to students in a sequence corresponding to the level of their individual development. This contributes to a more efficient mastering of the studied material.

A third example of the most successful implementation of these technologies concerns the use of 3D modelling of oil and gas fields' development. In this case, work in teams and under the guidance of teachers enables qualitative management of work taking into account industry requirements and standards, and to articulate and formalize a wide range of actual problems. Moreover, the performed works are the real industrial problems, and therefore students' interest greatly increases, there appear awareness of importance and relevance of the complex of knowledge that is offered to students throughout the course of study at the university, from the fundamentals of higher mathematics to economics. Students also acquire skills of teamwork and ability to correctly assign tasks, to find a common language with other experts in the subject area, etc. [11].

As one more example that could be given is the use of practice-oriented approach in designing coursework in "Power Engineering", both as a form of classroom activities and independent work, on the basis of the studied theoretical material and considering competences identified in the Federal State Educational Standards. Problemoriented focus of the learning process for the solution of tasks (problems) using the training projects method, reproducing situations that future engineers may encounter in their professional activities, develops students' skills to make them able to cope with various professional challenges in their field. Throughout the whole training period the so-called system of through designing coursework is implemented, that is a scheme of a smooth transition from 
one learning stage to another, with gradual complication of educational information content, succession of levels of requirements for the scope and depth of mastering knowledge and skills. The final result of learning for each student is an independently developed design of a boiler unit (boiler system) with the acquisition of skills and competences needed for work in a design department. The sequence and content of milestone course projects reproduces the activities of such departments. This system ensures a close relationship of the entire system of training with future professional activity and thus the formation of professional and personal competencies [12].

These are just a few examples of the use of active technologies in the educational process at TPU. Almost every department uses these methods, but this work has not yet acquired a systemic nature. As a step forward in this direction since 2012 Tomsk Polytechnic University have been testing CDIO principles on three pilot bachelor programmes entirely in its 3 institutes, namely, Institute of Natural Resources, Institute of Physics and Technology, and Institute of Power Engineering.

The fact that TPU graduates are in high demand in all regions of Russia as well as in the foreign countries could serve as confirmation of the effectiveness of expanding practice-based learning use in TPU. Traditionally TPU graduates are in greatest demand by enterprises of fuel and energy complex, chemical and petrochemical industry, oil and gas branch, high-tech manufacturing and other sectors of the economy.

In 2013 for 1,609 graduates 2,521 specialists were needed. At the request of graduates, 1,337 of them were employed, that is $93 \%$ of the graduation number, including 1,097 people employed on the basis of contracts and applications from enterprises. The largest share of graduates is employed in manufacturing industry - $23 \%$, followed by mining - $18 \%$ and production and distribution of electricity, gas and water - $12 \%$ [13].

As for the opinion of TPU graduates about the quality of educational process and the prospects of future employment, the results of the 2012 survey (information and analytical report on the 2013 survey results is currently in preparation) showed that graduates estimate well the practical knowledge and skills obtained in the course of training in TPU: their own practical skills and knowledge of modern production technologies -4.1 points each (hereinafter - out of 5, where 5 is maximum), their own communication skills and ability to work in teams - 4.6 points, and, what is particularly encouraging, their professional knowledge - 4.4 points, and knowledge of modern engineering -4.4 points.

At the end of the questionnaire the respondents were asked if they intend to recommend our university to their relatives and friends. The survey showed that the vast majority of all respondents answered positively to the question $(93.2 \%)$, which is an evidence of the high degree of graduates' satisfaction with their training at TPU in general [14], and employability is becoming increasingly important in the choice of university.

\section{REFERENCES}

[1] The London Communique "Towards the European Higher Education Area: responding to challenges in a globalised world", May 2007.
[2] Bologna Declaration, The European Higher Education Area, Joint Declaration of the European Ministers of Education, Bologna, 19 June 1999.

[3] Recommendations of the All-Russian Scientific and Practical Conference "Approaches to Development of the National Doctrine of Engineering Education of Russia in the New Industrialization", Tomsk, Russia, 4-6 December 2012. Available at http://aeer.ru/ru/conf1.htm. Accessed October 24, 2013.

[4] N. Shatalova. "All on storm! National Doctrine of Engineering Education of Russia is only to be developed". Poisk. Weekly newspaper of scientific community. Education. №51 (2012). Available at http://www.poisknews.ru/theme/edu/4824/. Accessed October 24, 2013.

[5] Embbeding Emploaybility into Curriculum. Learning \& Employability Series. Series One. The Higher Education Academy, April 2006.

[6] Career Development Leaning and Employability. Learning \& Employability Series. Series Two. The Higher Education Academy, July 2006.

[7] Re-engineering engineering education in Europe/edited by Claudio Borri and Francesco Maffioli. Firenze: Firenze University Press, 2007.

[8] The Aalborg PBL model - Progress, Diversity and Challenges. Anette Kolmos, Flemming K. Fink and Lone Krogh (eds.). Aalborg: Aalborg University Press, 2004.

[9] What is an effective approach to introducing PBL/POPBL in an institution : a model for making the change to PBL/POPBL as an alternative approach to Higher Education institutions. / Moesby, Egon. Aalborg : Institut for Samfundsudvikling og Planlægning, Aalborg Universitet, 2008. 185 p.

[10] Worldwide CDIO Initiative. Available at http://www.cdio.org. Accessed October 24, 2013.

[11] E.N. Belomestnova, A.N. Dreval, A.V. Kovalenko, N.V. Kozlova, M.G. Minin. Modern learning technologies in higher education. Tomsk: TPU, 2009,129 p.

[12] A.A. Saprykin, S.V. Khatkova. "Problems of future engineers training for professional activity in the today labour market conditions". Proceedings of the Scientific and Methodical Conference "Cycle training of specialists: international CDIO concept and TPU education programmes standards", Tomsk, Russia, 26-30 March 2013. Available at http://portal.tpu.ru/science/konf/methodconf. Accessed October 24, 2013.

[13] Results of 2013 TPU graduates employment. Available at http://portal.tpu.ru/departments/otdel/oopt/info/itogi2013/Tab. Accessed October 24, 2013.

[14] "Opinion of TPU graduates about the quality of education and future prospects of employment". Information and analytical report on the survey result. Tomsk: TPU, 2012. Available at http://portal.tpu.ru:7777/departments/otdel/oopt/info/Tab1/otchet_ 2012.pdf. Accessed October 24, 2013.

\section{AUTHORS}

A. Chuchalin is with National Research Tomsk Polytechnic University, Tomsk, Russia (chai@tpu.ru)

M. Minin, is with National Research Tomsk Polytechnic University, Tomsk, Russia (minin@tpu.ru)

N. Vyuzhanina is with National Research Tomsk Polytechnic University, Tomsk, Russia (nyv@tpu.ru)

This article is an extended and modified version of a paper presented at the 16th International Conference on Interactive Collaborative Learning (ICL2013) and 42nd IGIP International Conference on Engineering Pedagogy, held from 25 to 27 September 2013 at Kazan National Research Technological University, in Kazan, Russia.Submitted, November, 30, 2013. Published as resubmitted by the authors on March, 17, 2014. 